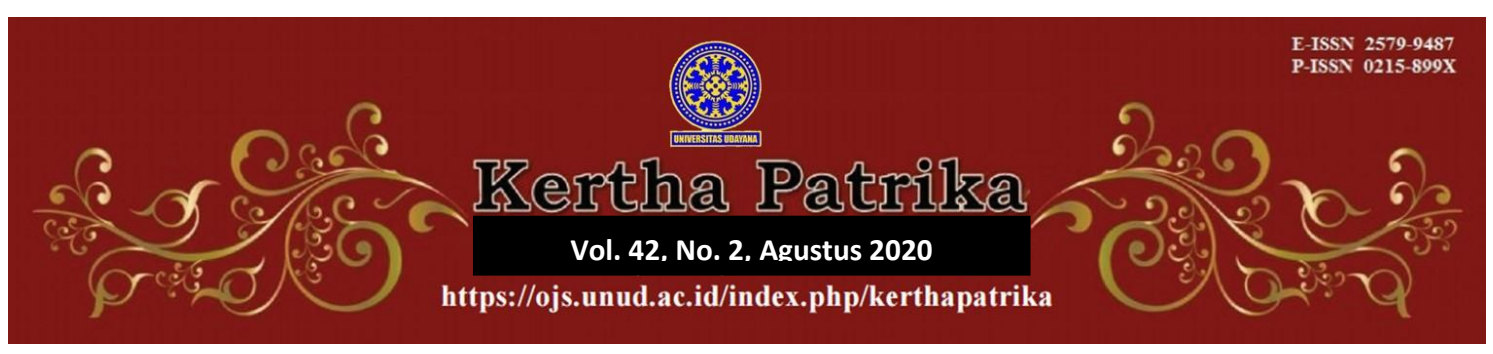

\title{
Illegal Fishing dalam Kajian Hukum Nasional dan Hukum Internasional: Kaitannya dengan Kejahatan Transnasional
}

\section{Desia Rakhma Banjarani ${ }^{1}$}

1Fakultas Hukum Universitas Lampung, E-mail: Desiarahma7@gmail.com

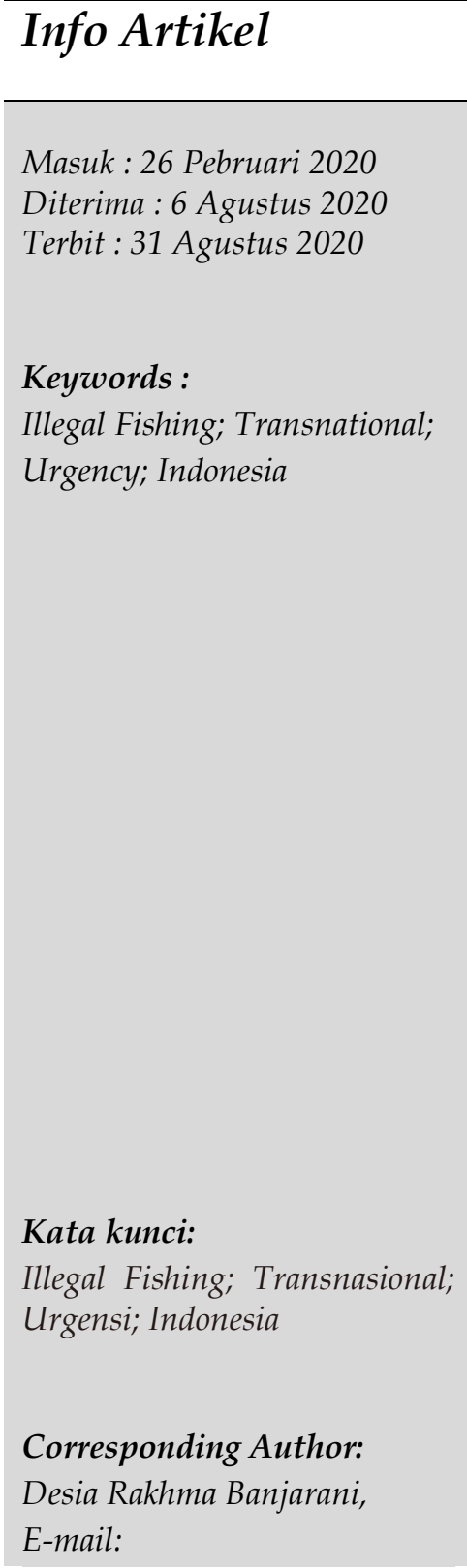

\begin{abstract}
Illegal fishing practices are transnational in nature, which are not so easy to prevent and eradicate without international cooperation. Several international treaties both in the field of international maritime and fisheries law as well as international crimes have not categorized it as a transnational crime. This article discusses regulations that cover the issue of illegal fishing according to Indonesian national law and international law and examines the urgency of countermeasuring illegal fishing as a transnational crime. This article is a normative legal research with a statutory approach that explores the relevant national and international legal instruments which analyzed using descriptive methods. The results indicated that illegal fishing has been strictly regulated both in national and international law, although international law has not categorized illegal fishing as a crime that has cross-border characteristics. Therefore, there is an urgency to countermeasuring illegal fishing through international cooperation. In terms of the implementation of Indonesian national law, until now there seems to be lack of coordination between the national government and regional governments in establishing a mechanism related to efforts to prevent and eradicate illegal fishing.
\end{abstract}




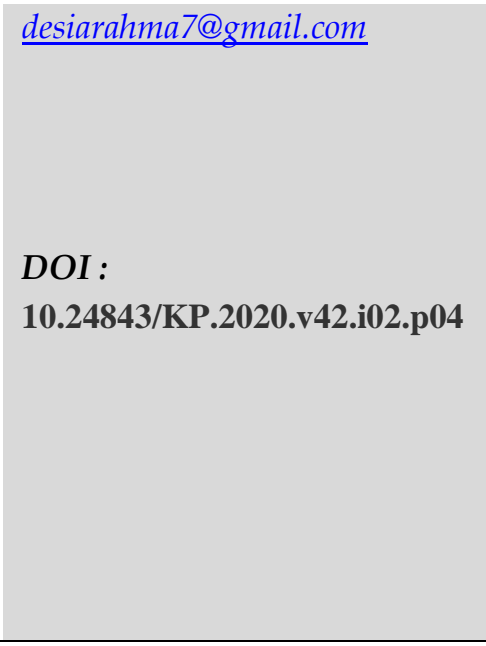

\begin{abstract}
penelitian hukum normatif dengan pendekatan perundangundangan yang menelusuri instrumen hukum nasional dan internasional yang relevan yang dianalisis dengan metode deskriptif. Hasil penelitian menunjukkan bahwa Illegal Fishing sudah diatur secara tegas baik dalam hukum nasional maupun hukum internasional, kendatipun kukum internasional belum mengategorikan illegal fishing sebagai kejahatan yang memiliki karakteristik lintas batas Negara. Oleh karenanya, penanggulangan illegal fishing urgen dilakukan melalui kerjasama internasional. Dari segi implementasi hukum nasional Indonesia, hingga saat ininampaknya belum terdapat koordinasi antara pemerintah pusat dengan pemerintah daerah dalam menetapkan suatu mekanisme berkaitan dengan upaya pencegahan dan pemberantasan illegal fishing.
\end{abstract}

\section{Pendahuluan}

Sebagaimana yang disebutkan dalam Pasal 25A Undang-Undang Dasar Negara Republik Indonesia Tahun 1945 (UUD NRI 1945) bahwa Indonesia adalah Negara kepulauan, ketentuan ini menegaskan bahwa Indonesia memiliki wilayah laut yang luas dan terbagi dalam pulau-pulau. ${ }^{1}$ Laut Indonesia terdiri dari $2,7 \mathrm{~km}^{2}$ wilayah Zona Ekonomi Eksklusif atau ZEE dan 3,2 juta $\mathrm{km}^{2}$ wilayah laut territorial, sehingga menurut UNCLOS 1982 total luas laut Indonesia adalah 5,9 juta km². Fakta ini menunjukkan bahwa Indonesia memiliki potensi laut yang cukup besar bahkan hingga dapat menjadi salah satu aspek penunjang perekonomian Indonesia. ${ }^{2} \mathrm{Hal}$ ini dapat terlihat pada potensi ekonomi pada sektor perikanan mencapai US\$ 82 miliar per tahun. Sehingga dapat dikatakan bahwa sektor kelautan dan perikanan dapat dijadikan sektor andalan bagi perekonomian di Indonesia. ${ }^{3}$ Namun pada kenyataannya pengembangan sector perikanan untuk perekonomian Indonesia harus tertunda dikarenakan maraknya praktik Illegal Fishing yang terjadi di Indonesia.

Salah satu definisi Illegal Fishingdikemukakanoleh Kementrian Kelautan dan Perikanan Indonesiayaitu Illegal Fishingatau Illegal, Unreported dan Unregulated (IUU) secara harfiah merupakan kegiatan perikanan yang dilarang dan tidak diatur dalam peraturan hukum yang sah, serta kegiatan perikanan yang tidak terdaftar dan terlaporpada lembaga perikanan yang diakui oleh pemerintah. ${ }^{4}$ Praktek illegal fishing ini telah diatur dalam peraturan Indonesia yaitu dalam UU No. 45 Tahun 2009 tentang Perikanan. ${ }^{5}$ Selain itu, pengaturan tentang Illegal Fishing ini juga telah menjadi isu lama

${ }^{1}$ Indra, Mexsasai. (2013). Urgensi Pengelolaan Wilayah Perbatasan Dalam Kaitannya dengan Kedaulatan Negara Kesatuan Republik Indonesia. Jurnal Selat, 1 (1), 13-18, h. 13.

2 Lasabuda, Ridwan. (2013). Tinjauan Teoritispembangunan Wilayah Pesisir Dan Lautan Dalam Perspektif Negarakepulauanrepublik Indonesia. Jurnal Ilmiah Platax, 1 (2), 92-101, https://doi.org/10.35800/jip.1.2.2013.1251, h. 92.

${ }^{3}$ Zebua, N. D. \&Ramli. (2014).Analisis Pengaruh Jumlah Armada, Jumlah Nelayan, Pdrb, Dan Investasi Terhadap Produksi Perikanan di Wilayah Nias (Analisis Data Panel). Jurnal Ekonomi dan Keuangan, 2 (8), 463-474, h. 465.

${ }^{4}$ Mahmudah, Nunung. (2015).Illegal Fishing. Jakarta: Sinar Grafika, h. 80.

${ }^{5}$ Barama, Michael. (2016). Menuju Efektivitas Uu No. 45 Tahun 2009 Tentang Perikanan Dalam Pelaksanaannya. Jurnal Hukum Unsrat, 22 (6), 1-13, h. 5. 
dalam lingkup hukum internasional yang kemudian terbentuk suatu kerangka hukum internasional yang melarang praktek illegal fishing, pengaturan tersebut termuat dalam United Nations Convention on the Law of the Sea atau UNCLOS yang telah disahkan pada 10 Desember 1982, dan kemudian diratifikasi oleh Indonesia dalam UU No. 17 tahun 1985.6

Dalam skala global, Illegal Fishing menjadi masalah besar hingga sangat sulit dihitung berapa banyak jumlah praktiknya. Illegal Fishing ini telah menjadi masalah khusus di negara-negara berkembang, dimana strategi manajemen perikanan tidak dikembangkan dengan baik, atau penegakkan peraturan hukum tentang perikanan yang terbatas. Bahkan terhitung kerugian secara global akibat Illegal Fishing ini diperkirakan antara US \$10 miliar dan US \$23,5 miliar setiap tahun. ${ }^{7} \mathrm{Hal}$ ini dikarenakan, secara keseluruhan total penangkapan ikan secara illegal yang tidak terdaftar di seluruh dunia mencapai 26 juta metrik ton ikan per tahun, bernilai hingga $\$ 23,5$ miliar. Jumlah ini setara dengan lebih dari 1.800 pon ikan yang ditangkap secara liar atau dicuri dari laut setiap detik. Sehingga hampir 90 persen ikan didunia telah dieksploitasi sepenuhnya atau dieksploitasi secara berlebihan. ${ }^{8}$

Illegal Fishing di Indonesiabukan merupakan hal baru. Praktik ini sering kali terjadi di wilayah laut Indonesia dengan ditemukannya kapal asing yang melakukan kegiatan perikanan di laut Indonesia, bahkan hingga mengakibatkan kerugian bagi Indonesia yakni sekitar Rp.300 triliun pertahun. ${ }^{9}$ Kegiatan illegal fishing pada wilayah laut di Indonesia dilakukan oleh nelayandari berbagai negara tetangga yang ada di sekitar laut Indonesia. Kegaiatan illegal ini dilakukan dengan berbagai modus demi mendapatkan keuntungan berlipatganda dari hasil penjualan ikan secara ilegal. ${ }^{10}$

Illegal fishing yang terjadidi wilayah laut Indonesia dilakukan dan beroperasi secara sistematis dan berkelanjutan. Selain itu, kegiatan illegal ini tidak begitu saja berdiri sendiri, namun telah masuk ke dalam suatu jaringan kejahatan transnasional atau lintas batas negara. ${ }^{11}$ Dengan adanya pelaku illegalfishing dari negara lain yang melakukan tindakan pelanggaran hukum di bukan negaranya, serta adanya jaringan yang melewati batas-batas negara, maka dapat dikatakan bahwa illegalfishingtelah masuk kedalamkejahatan lintas negara (transnationalcrime). Kejahatan yang bersifat

\footnotetext{
${ }^{6}$ Kurnia, Ida.(2008). Penerapan Unclos 1982 Dalam Ketentuan Perundang-Undangan Nasional, Khususnya Zona Ekonomi Eksklusif Indonesia. Jurnal Hukum Prioris, 2 (1), 42-49, h. 42.

${ }^{7}$ Seafish. (2012).The Seafish Guide to Illegal, Unreported, and Unregulated Fishing (IUU).Grimsby: The Authority on Seafood, h. 2.

8 Trusts, Pew. (2017). "How to End Illegal Fishing from Coastal Waters to the High Seas, Criminals are Robbing the Oceans and Hurting Economies." A Brief from the PEW Charitable Trusts, h. 1.

9 Kemeterian Kelautandan Perikanan.(2015). Illegal Fishing No More! Komitmen Serius Pemerintah Perangi Illegal Fishing.Majalah Mina Bahari, Edisi 1,p. 14.

${ }^{10}$ Muhamad,Simela Victor.(2012).Illegal Fishing di Perairan Indonesia: Permasalahan dan Upaya Penanganannya Secara Bilateral di Kawasan.Politica, 3 (1), 59-85, 10.22212/jp.v3i1.305, h. 60.

11 Wahjono, Pujo. (2010). Transnational Crime and Security Threats in Indonesia.Strategy Research Project, US Army War College, Pennsylvania. Lihat juga Graham, Euan. (2011), "Transnational Crime in the Fishing Industry: Asia's Problem?".RSIS Commentaries, 622, S. Rajaratnam School of International Studies, Nanyang Technological University, Singapore.
} 
lintas batas negara telahmenjadi salah satu permasalahan serius yang dihadapi Indonesia. ${ }^{12}$

Illegal fishing dapat dikategorikan sebagai salah satu jenis kejahatan transnasional atau transnationalcrime dikarenakan unsurnya yang melibatkan lebih dari satu negara, yaitu perencanaan, persiapan dan akibat dari kejahatan tersebut telah melibatkan lebih dari satu negara. Hal ini sebagaimana yang termuat dalam Pasal 3 Konvensi UNTOC yang menegaskan tentang unsur-unsur kejahatan transnasional. ${ }^{13}$ Dikarenakan sifatnya yang melampaui batas-batas Negara, maka masyarakat internasional mulai memberikan perhatian lebih terkait isulllegal fishing. Haltersebut dikarenakan jikakegiatan ilegal ini tidak serius ditangani oleh masyarakat internasional, maka akan mengancamkelestarian ekosistem laut dan sumber daya perikanan karena Illegal fishingsendiri telah terjadi di berbagai belahan dunia. ${ }^{14}$

Dengan demikian, maka dapat terlihat bahwaillegal fishing memiliki sifat transnasional maka akan sulit untuk mencegah dan memberantasnya tanpa kerjasama internasional antar negara di dunia. Hal tersebut didasarkan bahwa hingga saat ini Illegal Fishing belum termasuk ke dalam salah satu kategori kejahatan transnasional berdasarkan UNTOC 2000. Selain itu, hingga saat ini berbagai konvensi internasional di bidang hukum laut, perikanan, dan berbagai konvensi pidana internasional belum menggolongkan illegal fishing sebagai kejahatan transnasional. ${ }^{15}$ Memasukkan illegal fishing sebagai kejahatan transnasional merupakan hal penting karena akan memudahkan proses kerjasama internasional antar negara maupun daerah dalam rangka pemberantasan kejahatan transnasional. Dengan demikian diperlukan adanya analisis terkait "Tinjauan Illegal Fishing dalam Kajian Hukum Nasional dan Hukum Internasional: Kaitannya dengan Kejahatan Transnasional".Adapun permasalahan yang akan di bahas dalam artikel ini yaitu bagaimana pengaturan terkait Illegal Fishing menurut hukum nasional dan hukum internasional? Dan bagaimana urgensi penanggulangan Illegal Fishing sebagai kejahatan transnasional?

\section{Metode Penelitian}

Metode penelitian yang digunakan dalam penelitian ini yaitu metode penelitian hukum normatif, dengan pendekatan peraturan konvensi dan undang-undang. Penelitian ini menggunakan data hukum sekunder, yaitu undang-undang yang berkaitan dengan masalah, yaitu Kitab Undang-Undang Hukum Pidana atau KUHP, Convention Against TransnationalOrganized Crime 2000, UU No. 45 tahun 2009 tentang Perikanan dan artikel ilmiah hukum lainnya yang relevan dengan penelitian ini. Selain

\footnotetext{
${ }^{12}$ Muhamad, Simela Victor.Op.Cit., h. 61

${ }^{13}$ Convention Against Transnational Organized Crime atau UNTOC adalah konvensi internasional yang dibentuk oleh Perserikatan Bangsa-Bangsa atau PBB pada tahun 2000 di Palermo, Italia. Pembentukan konvensi ini dilakukan PBB melalui Resolusi PBB No. 55/25 tentangpenanggulangan kejahatan transnasional yang terorganisasi.

${ }^{14}$ MRAG/FERR. (2008).The Global Extent of Illegal Fishing.Fisheries Ecosystems Restotration Research, University of British Columbia: Fisheries Centre, h. 2.

${ }^{15}$ Bondaroff, Teale N. Phelps.(2015).The Illegal Fishing and Organized Crime Nexus: Illegal Fishing As Transnational Crime. Netherlands: The Global Intiative Against Transnational Organized Crime, h. 51
} 
itu, metode analisis yang digunakan dalam penelitian ini adalah metode analisis deskriptif.

\section{Pembahasan}

\subsection{Pengaturan Illegal Fishing Menurut Hukum Nasional dan Hukum Internasional}

Illegal fishingmerupakan dua kata dalam bahasa inggris yaituillegal dan fishing. Kata "Illegal" secara terminologi diartikan sebagai sesuatu yang terlarang, ditentang dan tidak sah menurut hukum, sedangkan untuk kata "Fish" berarti ikan dan "fishing" artinya menangkap atau memancing ikan sebagai mata pencaharian. ${ }^{16}$ Sehingga Illegal Fishingmemiliki arti sebagai kegiatan menangkap ikan oleh nelayan yang dilakukan secara tidak bertanggung jawab dengan melanggar hukum dan peraturan yang berlaku. Adapun salah satu contoh kegiatan nelayan yang melanggar hukum dalam menangkap ikan yaitu seperti penangkapan yang menggunakan alat tangkap yang berpotensi merusak ekosistem laut. ${ }^{17}$ Penangkapan ikan secara ilegal, tidak terlapor dan melanggar hukum dikenal dengan istilah IUU(Illegal, Unreported dan Unregulated).Istilah ini merujuk pada kebijakan dan pengelolaan perikanan dalam setiap kegiatanpengambilan ikan di laut dan dilakukan dengan cara bertentangan atau menghindari hukum terkait konservasi dan pengelolaan perikanan domestik dan internasional. ${ }^{18}$

Penyebab terjadinya illegal fishing disebabkan oleh beberapa hal, yakni;peningkatan permintaan produk perikanan di pasar lokal maupun global, subsidi sektor perikanan yang over kapasitas, berkurangnya kemampuan negara untuk mengkontrol kapal perikanan, dan tidak efektifinya kontrol, pemantauan terhadap kegiatan perikanan. ${ }^{19}$ Adapun pengaturan terkait Illegal Fishing menurut Hukum Internasional antara lain yaitu: ${ }^{20}$

a. United Nations Convention on the Law of the Sea 1982 Konvensi Perserikatan BangsaBangsa (PBB) tentang Hukum Laut Tahun 1982.

b. Food and Agreeculture Organication Compliance Agreement 1993.

c. United Nations Implementing Agreement 1995 Pada intinya UNIA 1995.

d. Code of Conduct For Responsible Fisheries 1995.

${ }^{16}$ Echols, John M.,\& Shadily, Hassan.(2002).Kamus Inggris Indonesia. Jakarta: Gramedia Pustaka Utama, h.. 311

17 Maryani, H. \& Nasution, A. (2019). Rekonsepsi Model Pemberantasan Illegal Fishing di Perairan Indonesia (Analisis Perspektif Hukum Internasional).Jurnal Legislasi Indonesia. 16 (3), 380-391, h. 383

18 Rosello, Mercedes.(2016). Illegal, Unreported and Unregulated Fishing Control in the Exclusive Economic Zone: a Brief Appraisal of Regulatory Deficits and Accountability Strategies.CIRR, 22 (75), 39-68, https:/ / doi.org/10.1515/cirr-2016-0002, h. 40.

19

DikdikMohamad.(2007).“CombatingIllegal,Unreported,andUnregulatedFishinginIndonesia nWaters:Need forFisheriesLegislativeReform," DisertasiWolonglongUniversity, h.125.

${ }^{20}$ Maryani, H. \& Nasution, A.Op.Cit., h. 384. 
e. International Plan of Action to Prevent, Deter and Elimination Illegal, Unrefortet and Unregulated Fishing 2001 (IPO on IUU Fishing 2001).

Menurut hukum nasional atau hukum di Indonesia, pengaturan terkait Illegal Fishing yaitudiantaranya:

a. UURI No. 45 Tahun 2009 tentang Perikanan.

b. UU RI No. 5 tahun 1983 tentang Zona Ekonomi Ekslusif Indonesia.

c. UU RI No. 21 Tahun 1992 Tentang Pelayaran

d. UU RI No. 6 Tahun 1996 Tentang Perairan Indonesia

e. UU RI No. 31 Tahun 2004 tentang Perikanan.

Penenggelaman kapal asing merupakan salah satu bentuk upaya pemerintah Indonesia dalam menanggulangidan memberantas illegal fishing. Pemerintah Indonesiamemberikan mandat kepada petugas yang mengawasi laut Indonesia agar dapat melakukan penindakan tegas, salah satunya dengan menenggelamkan kapal asing yang melakukan praktikillegal fishingdi wilayah perairan Indonesia. Hal ini dilakukan berdasarkan pada UU RI No. 31 Tahun 2004 tentang Perikanan, serta diatur pula dalam Pasal 45 UU RI No. 8 Tahun 1981 tentang Kitab Undang-Undang Hukum Acara Pidana.Kebijakan penenggelaman kapal asing yang melakukan illegal fishing merupakan tindakan khusus pemusnahan barang bukti. Pemusnahan ini dapat dilakukan dengan dikaramkan,dibakar, ditenggelamkan, dan diledakan. ${ }^{21}$

Adapun tindak pidana perikanan juga diatur dalam Kitab Undang-Undang Hukum Pidana atau KUHP, yaitu dalam Buku II KUHP tentang Kejahatan pada Bab XXIX Tentang Kejahatan Pelayaran (438-479), serta dalam Buku III tentang Pelanggaran yaitu dalamBab IX Tentang Pelanggaran Pelayaran (60-569). Ketentuan yang diatur dalam KUHP tidak secara khusus tentang illegal fishing,tetapi lebih mengatur tentang kejahatan pelayaran. NamunPasal 103 KUHP mengatur bahwa ketentuan-pada Bab I sampai Bab VIII KUHP dapat berlaku bagi perbuatan yang menurut undang-undang atau peraturan lain diancam dengan pidana, kecuali terdapat ketentuan lainnya dalam undang-undang tersebut. Kemudian apabila suatu perbuatan termasuk dalam aturan pidana umum, dan termasuk juga dalam aturan pidana khusus, maka hanya aturan pidana yang khusus itulah yang dapat dikenakan oleh pelaku, hal ini sebagaimana yang diatur dalam Pasal 63 ayat 2 KUHP. Ketentuan ini tentu mengacu pada masalah perikanan yang diatur diluar KUHP yaitu UU RI No. 45 tahun 2009. ${ }^{22}$ Adapun pemidanaan pelaku illegal fishing dapat dilakukan melalui dua cara, yakni:23

a. Pemidanaan melalui saranapenal yang diatur dalam Pasal 93, Pasal 94, Pasal 94A, Pasal 100 A UU RI No. 45 tahun 2009 jo UU RI No. 31 tahun 2004 tentang Perikanan. Berdasarkan ketentuan-ketentuan tersebut, maka pelaku illegal fishing diancam sanksi pidana seperti denda atau penjara. Hal ini sebagaimana yang diatur dalam Pasal 64 dan Pasal 85 UU RI No. 45 tahun 2009 jo UU RI No. 31 tahun 2004.Adapun bagi pelaku illegal fishingdiancam denganpenjara sekurang-

${ }^{21}$ Haryanto\&Setiyono, Joko. (2017)..Kebijakan Penenggelaman Kapal Asing Pelaku Illegal Fishing Oleh Pemerintah Indonesia Dalam Persfektif Hukum Pidana Internasional.Jurnal Law Reform, 13 (1), 70-85, https://doi.org/10.14710/lr.v13i1.15952,74

22 Suka'arsana, I Komang.(2018). Penegakan Hukum Terhadap Tindak Pidana Pencurian Ikan.Jurnal Hukum Pidana dan Pembangunan Hukum,1 (1), 1-5, h.3.

${ }^{23}$ Ibid., h.5-8 
kurangnya 5 tahun dan maksimal 10 tahun beserta denda sebesar Rp. 10.000.000.000.Kemudian terdapat ketentuan lain yang diatur dalam Pasal 93, Pasal 94 dan Pasal 94 A UU RI No 45 tahun 2009 jo UU RI No. 31 tahun 2004, yang menyatakan bahwa setiap orang yang melakukan pengangkutan atau penangkapan ikan tanpa dilengkapi dengan SIUP, ${ }^{24}$ SIPI ${ }^{25}$ dan SIKPI ${ }^{26}$, maka diancam pidana penjara sekurang-kurangnya 5 tahun dan maksimal 7 tahun dengan denda minimal sejumlah Rp. 1.500.000.000 dan maksimal $\mathrm{Rp}$ 20.000.000.000. Adapun ketentuan bagi nahkoda yang tidak memiliki surat ijin berlayar namun mengendarai kapal pengangkutan dan penangkapan ikan, maka diancam pidana penjara 1 tahun dengan denda Rp. 200.000.000.

b. Pemidanaan melalui sarana non penal yaitumelalui penjatuhan kebijakan sosial yang terintegrasi pada pembangunan hukum nasional dengan melakukan tindakan khusus oleh kapal pengawas RI, dengan bukti permulaan melakukan pembakaran dan/atau penenggelaman kapal.

\subsection{UrgensiIllegal Fishing Sebagai Kejahatan Transnasional}

Kejahatan transnasional menurutI Wayan Parthiana merupakan kejahatan yang melintasi batas-batas wilayah dari suatu negara. Tempat kejadian, tujuan kejahatan dan akibat yang muncul dari kejahatan merupakan beberapa aspek kejahatan transnasional yang tidak memiliki batas wilayah tertentu. ${ }^{27}$ Transnasional merupakan istilah khusus yang mengacu pada individu yang melakukan suatu kejahatan, sehingga individu tersebut dapat mempertanggungjawabkan kejahatan yang dilakukannya dengan berdasarkan pada hukum internasional dan hukum nasional suatu negara. ${ }^{28}$ Karakteristik "transnational crimes" diatur dalarn Konvensi Menentang Kejahatan Transnasional Terorganisasi (Convention Against Transnational Organized Crimes) atau dikenal dengan Konvensi Palermo (2000). ${ }^{29}$ Dalam pasal 3 Konvensi UNTOC menegaskan bahwa unsur-unsur kejahatan transnasional adalah sebagai berikut:

a. Dilakukan lebih dari satu wilayah teritorial suatu negara;

b. Kejahatan tersebut dikendalikan, dipersiapkan, diarahkan dan direncanakan pada satu negara tertentu, namun pelaksanaan kejahatan tersebut dilakukan di negara berbeda;

c. Kejahatan yang dilaksanakan dalam satu wilayah negara, namun melibatkan individu atau kelompok terorganisasi yang melakukan kejahatan di Negara lain; atau

d. Kejahatan yang dilakukan di satu negara, namun akibat kejahatan tersebutmenimpa negara lain.

24Surat Izin Usaha Perdagangan.

${ }^{25}$ Surat Izin Penangkapan Ikan.

${ }^{26}$ SuratIzin Kapal Pengangkut Ikan.

27 Agustina, Shinta. (2006). Perdagangan Perempuan dan Anak sebagai Kejahatan Transnasional: Permasalahan dan Penanggulangannya di Indonesia.Jurnal Hukum Projustitia24 (1), 47-62, h. 50.

28 Indriati, Noer. (2009).Mutual Legal Assistance Treaties (Mlats) Sebagai Instrumen Pemberantasan Kejahatan Internasional. Jurnal Dinamika Hukum, 9(2), http://dx.doi.org/10.20884/1.jdh.2009.9.2.218, 103-110, h. 105.

29 Atmasasmita,Romli. (2007).Ekstradisi dalam Meningkatkan Kerjasama Penegakan Hukum.Jurnal HukumInternasional, 5 (1), 10.17304/ijil.vol5.1.145, 1-15, h.2. 
Kejahatan Transnasional sebagaimana yang telah PBB identifikasi dalam UNTOC terdiri dari 18 bentuk kejahatan yaituhuman trafficking (perdagangan orang), perdagangan organ tubuh manusia, perdagangan gelap pasukan dan senjata,illicit drug trafficking (penyelundupan obat), money laundering (pencucian uang),fraudulent bankruptcy,pencurian karya intelektual, corruption (korupsi), terrorism (terorisme),bribery of partyofficials (penyogokan pejabat partai), pembajakan pesawat, pencurian objek seni dan kebudayaan, pembajakan kapal laut,briberyof public (penyogokan pejabat publik), infiltration of legalbusiness (penyusupan bisnis), insurance fraud (penipuan perbankan dan asuransi), cybercrime, danenvironmental crime (kejahatan terhadap lingkungan). ${ }^{30}$

Pada suatu laporan yang diungkapkan oleh Global Financial Integrity menyatakan bahwa kejahatan transnasional merupakan bisnisdengan motivasi utamanya adalah menghasilkan uang. Pendapatan yang dihasilkan dari kejahatan transnasional diperkirakan berkisar antara US \$1,6 triliun dan \$2,2 triliun per tahun. Penghasilan ini tidak hanya digunakan untuk kepentingan pribadi para pelakunya, namun penghasilan dari kejahatan juga digunakan membiayai berbagai bentuk kejahatan transnasional lainnya. Oleh karena itu, kejahatan transnasional bukanlah kejahatan yang dapat diremehkan, karena kejahatan ini dapat mengancamperekonomian nasional suatu negara, bahkan dapat membahayakan kesehatan dan kesejahteraan masyarakat, hingga mengancam kerusakanlingkungan. ${ }^{31}$

Masyarakat internasional mulai menyadari bahaya dari praktik illegal fishing hingga membahasnya sebagai isu global yang baru dengan mengaktegorikan illegal fishing sebagai bentuk baru kejahatan transnasionalpada tahun 2000-an. ${ }^{32}$ Terlihat pada ditentukannya definisi illegal fishing sendiri yang telah dirumuskan oleh PBB sebagai kejahatan perikanan sebagai konsep hukum yang tidak jelas dan merujuk pada serangkaian kegiatan ilegal di sektor perikanan. Illegal Fishing sering bersifat transnasional dan terorganisir meliputi perdagangan ilegal, penipuan dokumen, perdagangan narkoba, dan pencucian uang. ${ }^{33}$

Pemerintah Indonesia sendiri terus mengadvokasi IUU Fishing untuk dikategorikan sebagai Kejahatan Terorganisir Transnasional (TOC) di tingkat internasional. Analisis dan evaluasi selama 11 bulan (ANEV) pada tahun 2015-2016, terdapat $1.132 \mathrm{kapal}$ penangkap ikan asing yang beroperasi di Indonesia dengan modus operandi penangkapan ikan secara ilegal namun melibatkan berbagai jenis kejahatan lain, termasuk penangkapan ikan secara berlebihan, penipuan pajak, penempaan dokumen lisensi kapal, narkotika dan perdagangan manusia, pencucian uang, dan sebagainya. Setelah audit kepatuhan dan Simposium Internasional Pertama tentang Ikan CRIME di Cape Town, 12-13 Oktober 2015, pemerintah Indonesia terus mendorong IUU fishing diakui sebagai bentuk kejahatan transnasional. Bentuk keseriusan pemerintah

\footnotetext{
${ }^{30}$ Convention Against TransnationalOrganized Crime 2000

${ }^{31}$ Global Financial Integrity.(2017).Transnational Crime and the Developing World. Washington: Global Financial Integrity, h. Xi.

32 Cozens,Peter. (2010).Maritime Security and Oceans Policy," dalam Maritime Security: International Law and Policy Perspectives from Australia and New Zealand. UK: Routledge, h. 155-171.

33 United Nations on Drugs and Crime.Fisheries Crimes. Viena, Austria: United Nations.p. 2.
} 
Indonesia menjadikan ilegal fishing sebagai kejahatan transnasional adalah dengan mempromosikan lebih banyak komitmen dan tindakan nyata oleh negara-negara lain dengan meningkatkan kerjasama internasional terkait illegal fishing. ${ }^{34}$

Pemerintah Indonesia melalui Kementerian Kelautan dan Perikanan terus melakukan berbagai upaya di tingkat internasional dalam sekuritisasi isu illegal fishing. Hal ini dapat terlihat saat Menteri Kelautan dan Perikanan Indonesia, Susi Pudjiastuti, yang mengahadirikonferensi kelautan PBB: Transnational Organized Crime in FisheriesIndustry bersama Norwegia, Interpol dan United Nations Officeon Drugs and Crime (UNODC). Saat konferensi tersebut, menteri Susi melakukan dialog dengan PBBdan meminta praktik Illegal Fishing ditetapkan oleh PBB sebagai salah satu dari kejahatan transnasional yang terorganisir. "Kita harus mengakui bahwa Illegal Unreported and Unregulated (IUU) Fishingini adalah kejahatan transnasional yang terorganisir karena operasinya didukung oleh kelompok terorganisir". ${ }^{35}$

Dengan demikian dapat terlihat bahwa unsur kejahatan transnasional dalam elemen kejahatan illegal fishing dan fishing crime ini menyebabkan dibutuhkan kerja sama internasional untuk mengatasinya. Hingga kini belum ada kerjasama internasional yang dapat dimanfaatkan Indonesia untuk memberantas illegal fishing dan fishing crime sebagai sebuah kejahatan yang memerlukan kerjasama internasional. Hukum internasional belum menjadikan illegal fishing sebagai kejahatan yang memiliki karakteristik lintas batas negara (transnasional organized crime). Begitu juga dengan koordinasi pencegahan dan pemberantasan illegal fishing dengan pemerintah daerah. Hingga kini belum terdapat koordinasi pemerintah pusat dengan pemerintah daerah, dalam menetapkan suatu mekanisme dan upaya pencegahan dan pemberantasan illegal fishing. ${ }^{36}$ Keterlibatan pemerintah pusat, pemerintah daerah dan masyarakat akan sangat menentukan aspek keberlakuan hukum secara efektif ${ }^{37}$, termasuk dalam hal terkait pencegahan da pemberantasan illegal fishing.

Diperlukan adanya kerjasama internasional antar negara untuk menetapkan illegal fishing sebagai kejahatan trasnasional karena dalam kejahatan illegal fishing bukan saja terdapat kejahatan yang bersifat tunggal tetapi berkaitan dengankejahatan lainyangberhubungandengankejahatan perikanan (fishing crime) seperti perdagangan manusia, pencucian uang, kerja paksa, kejahatan di bidang minyak dan gas bumi yang tentu memerlukan pendekatan konsep yang lain dari konsep saat

34 Taufik, Kinanti Kusumawardani. (2017). IUU Fishing as Transnational Organized Crime' Discourse: A Policy Argumentation Analysis.Paper prepared for presentation at the ISA International Conference, Hong Kong, June 17, h. .2

${ }^{35}$ Isnurhadi, M. Rizqi. (2017). "Sekuritisasi Illegal, Unreported, Unregulated Fishing (IUUF) di Perairan Indonesia di Era Pemerintahan Joko Widodo." Jurnal Hubungan Internasional,10 (2), 118-132, http:/ /dx.doi.org/10.20473/jhi.v10i2.7300, h.19.

${ }^{36}$ Pudjiastuti, Susi. "Fisheries Crime As Transnational Organized Crime".Makalah disampaikan pada Pertemuan di Singapura, 17 November 2015, h. 14.

${ }^{37}$ Sudiarawan, K. A., Tanaya, P. E., \& Hermanto, B. (2020). Discover the Legal Concept in the Sociological Study. Substantive Justice International Journal of Law, 3(1), 94-108, http://dx.doi.org/10.33096/sjijl.v3i1.69 
ini. ${ }^{38}$ Pentingnya mengidentifikasi kejahatan lintas negara ini selain dikarenakan semakin maraknya kasus illegal fishing yang terjadi di Indonesia dan melibatkan aspek hukum dari negara lain sehingga memerlukan penegakan hukum yang tepat. Hal tersebut dikarenakan dalam penegakan tersebut diperlukan kualifikasi jenis kejahatan yang sesuai agar tidak terjadi kesalahan dalam penempatan jenis kejahatan tersebut, dimana jika terjadi kesalahan maka akan berdampak pada kekeliruan dalam penempatan asas-asas hukum itu sendiri sebagai cita-cita menciptakan suatu keadilan. Jika terjadinya kesalahan dalam kualifikasi kejahatan maka penegakan hukum tersebut akan menyimpang dari tujuannya. Sebagaimana diketahui bahwa tujuan penegakan hukum formil merupakantercapainya kedamaian dalam masyarakat. ${ }^{39}$

Selain itu, jika terjadinya kesalahan dalam penempatan hukum tersebut maka pihak pelaku kejahatan juga akan mendapat keuntungan. Jika pelaku kejahatan tersebut dapat bebas dari penegakan hukum dikarenakan kesalahan kualifikasi kejahatan maka pelaku tersebut tidak dapat dituntut kembali, hal ini berdasarkan pada asas yang berlaku dalam hukum pidana yakni asas ne bis in idem. Asas ini menyatakan bahwaseseorang tidak dapat dituntut kembali atas suatu perbuatan yang dilakukannya dan telah diputus oleh hakim. ${ }^{40}$ Sehingga kejahatan tersebut akan semakin berkembang baik dalam lingkup kejahatan transnasional maupun kejahatan internasional, maka diperlukan suatu identifikasi yang membedakan dua jenis kejahatan tersebut berdasarkan ruang lingkupnya. Pentingnya penempatan asas-asas dalam hukum kejahatan transnasional karena dapat dijadikan alat analisis dalam rangka pencegahan dan pemberantasan kejahatan transnasional yang terjadi di Indonesia. ${ }^{41}$

Dengan demikian, maka diharapkan agar pemerintah Indonesia dapat terus berupaya menjalin kerjasama antar negara sebagai bentuk upaya pencegahan illegal fishing karena bagaimanapun Indonesia adalah negara kepulauan yang memiliki kekayaan ikan maka akan disayangkan apabila kekayaan itu justru dinikmati oleh pihak lain bukan dari warga Indonesia sendiri. Selain itu, sebaiknya Indonesia terus melakukan berbagai upaya di tingkat internasional agar illegal fishing dapat dikategorikan sebagai kejahatan transnasional oleh Perserikatan Bangsa-Bangsa.

\section{Kesimpulan}

Praktik Illegal Fishingmerupakan kejahatan lintas negara memiliki ancaman yang cukup besar. Illegal fishing tidak hanya melibatkan kejahatan tunggal melainkan dapat melibatkan berbagai tindakpidanaperikanan (fishing crime) lainnya seperti perdagangan manusia, pencucian uang, kerja paksa, kejahatan

\footnotetext{
${ }^{38}$ Risnain, M. (2017).Rekonsepsi Model Pencegahan dan Pemberantasan Illegal Fishing di Indonesia. Padjadjaran Jurnal Ilmu Hukum, 4 (2), 379-378, https://doi.org/10.22304/pjih.v4n2.a9 ,h. 380.

${ }^{39}$ Kallo, Syafruddin. (2012).Teori dan Penemuan Hukum. Medan: Universitas Sumatera Utara, h. 50.

40Pasal 76 (1) Kitab Undang-Undang Hukum Pidana.

${ }^{41}$ Atmasasmita, Romli. (2004). Pengaruh Konvensi Internasional terhadap Perkembangan AsasAsas Hukum Pidana Internasional.Makalah Pada Seminar Asas-Asas Hukum Pidana Nasional. Kerjasama UNDIP dan BPHN DEPKEH HAM RI, h. 2
} 
di bidang minyak dan gas bumi, narkotika, dan lain lain.Hukum nasional Indonesia dan hukum internasional sesungguhnya telah mengatur illegal fishing, bahkan memuat sanksi tegas bagi pelakunya. Hanya saja, praktik illegal fishing tetap saja masih terus berlangsung di Indonesia.Adanya sifat transnasional dalam elemen kejahatan illegal fishing dan fishing crime menyaratkandilakukannya kerja sama internasional untuk mengatasinya. Hingga kini belum ada kerjasama internasional yang dapat dimanfaatkan Indonesia untuk memberantas illegal fishing. Dari aspek pengaturan, Hukum internasional belum mengategorikanillegal fishing sebagai kejahatan yang memiliki karakteristik lintas batas negara (transnasional organized crime). Dari segi implementasi hukum nasional Indonesia,hingga saat ininampaknya koordinasi pemerintah pusat dengan pemerintah daerah berlum terlaksana dengan baik dalam menetapkan suatu mekanisme berkaitan dengan upaya pencegahan dan pemberantasan illegal fishing.

\section{A. Buku}

\section{DAFTAR PUSTAKA}

Bondaroff, Teale N. Phelps. (2015).The Illegal Fishing and Organized Crime Nexus: Illegal Fishing As Transnational Crime. Netherlands: The Global Intiative Against Transnational Organized Crime.

Echols, John M. \&Shadily, Hassan. (2002).Kamus Inggris Indonesia.Jakarta: Gramedia Pustaka Utama.

Kallo, Syafruddin. (2012).Teori dan Penemuan Hukum. Medan: Universitas Sumatera Utara.

Mahmudah, Nunung. (2015).Illegal Fishing. Jakarta: Sinar Grafika.

Seafish. (2012).The Seafish Guide to Illegal, Unreported, and Unregulated Fishing (IUU).Grimsby: The Authority on Seafood.

United Nations on Drugs and Crime.Fisheries Crimes. Viena, Austria: United Nations.

\section{B. Jurnal, Artikel, Makalah, dan Disertasi}

Agustina, Shinta. (2006). Perdagangan Perempuan dan Anak sebagai Kejahatan Transnasional: Permasalahan dan Penanggulangannya di Indonesia. Jurnal Hukum Projustitia, 24 (1), 47-62.

Atmasasmita, Romli. (2004). Pengaruh Konvensi Internasional terhadap Perkembangan Asas-Asas Hukum Pidana Internasional. Makalah pada seminar asasasas hukum pidana nasional. Kerjasama UNDIP dan BPHN DEPKEH HAM RI.

Atmasasmita, Romli. (2007). Ekstradisi dalam Meningkatkan Kerjasama Penegakan $\begin{array}{llll}\text { Hukum.Jurnal HukumInternasional, } & 5 & \text { (1), }\end{array}$ http://dx.doi.org/10.17304/ijil.vol5.1.145.

Barama, Michael. (2016). Menuju Efektivitas Uu No. 45 Tahun 2009 Tentang Perikanan Dalam Pelaksanaannya. Jurnal Hukum Unsrat, 22 (6), 1-13.

Graham, Euan. (2011). Transnational Crime in the Fishing Industry: Asia's Problem? RSIS Commentaries, 62, S. Rajaratnam School of International Studies, Nanyang Technological University, Singapore. 
Haryanto \& Setiyono, Joko. (2017). Kebijakan Penenggelaman Kapal Asing Pelaku Illegal Fishing Oleh Pemerintah Indonesia Dalam Persfektif Hukum Pidana Internasional. Jurnal Law Reform, 13 (1), 70-85. https://doi.org/10.14710/lr.v13i1.15952.

Indra, Mexsasai. (2013). Urgensi Pengelolaan Wilayah Perbatasan Dalam Kaitannya dengan Kedaulatan Negara Kesatuan Republik Indonesia.Jurnal Selat, 1 (1), 13-18.

Indriati, Noer. (2009). Mutual Legal Assistance Treaties (Mlats) Sebagai Instrumen Pemberantasan Kejahatan Internasional. Jurnal Dinamika Hukum, 9 (2), 125-134. http://dx.doi.org/10.20884/1.jdh.2009.9.2.218.

Isnurhadi, M. Rizqi. (2017). Sekuritisasi Illegal, Unreported, Unregulated Fishing (IUUF) di Perairan Indonesia di Era Pemerintahan Joko Widodo. Jurnal Hubungan Internasional,10(2), 13-27. http://dx.doi.org/10.20473/jhi.v10i2.7300.

Kementerian Kelautandan Perikanan. (2015). Illegal Fishing No More! Komitmen Serius Pemerintah Perangi Illegal Fishing. Majalah Mina Bahari,edisi 1.

Kurnia, Ida. (2008). Penerapan Unclos 1982 Dalam Ketentuan Perundang-Undangan Nasional, Khususnya Zona Ekonomi Eksklusif Indonesia. Jurnal Hukum Prioris, 2 (1), 42-49.

Lasabuda, Ridwan. (2013). Tinjauan Teoritispembangunan Wilayah Pesisir Dan Lautan Dalam Perspektif Negarakepulauanrepublik Indonesia. Jurnal Ilmiah Platax, 1 (2), 92-101, https:/ / doi.org/10.35800/jip.1.2.2013.1251.

Maryani, Halimatul\& Nasution, Adawiyah. (2019). Rekonsepsi Model Pemberantasan Illegal Fishing di Perairan Indonesia (Analisis Perspektif Hukum Internasional). Jurnal Legislasi Indonesia, 16 (3), 379-391.

MRAG/FERR. (2008). The Global Extent of Illegal Fishing.Fisheries Ecosystems Restotration Research.University of British Columbia: Fisheries Centre.

Muhamad, Simela Victor. (2012).Illegal Fishing di Perairan Indonesia: Permasalahan dan Upaya Penanganannya Secara Bilateral di Kawasan.Politica,3 (1), 59-86. https://doi.org/10.22212/jp.v3i1.305.

Pudjiastuti, Susi. (2015). Fisheries Crime as Transnational Organized Crime.Makalah disampaikan pada Pertemuan di Singapura.

Risnain, M. (2017).Rekonsepsi Model Pencegahan dan Pemberantasan Illegal Fishing di Indonesia. Padjadjaran Jurnal Ilmu Hukum, 4(2),379-398 https://doi.org/10.22304/pjih.v4n2.a9.

Rosello, Mercedes. (2016). Illegal, Unreported and Unregulated Fishing Control in the Exclusive Economic Zone: a Brief Appraisal of Regulatory Deficits and Accountability Strategies. CIRR,22(75), 39-68. 10.1515/cirr-2016-0002.

Sodik,

DikdikMohamad. (2007).CombatingIllegal,Unreported, andUnregulatedFishinginIndonesianWaters:N eed forFisheriesLegislativeReform.DisertasiWolonglongUniversity.

Sudiarawan, K. A., Tanaya, P. E., \& Hermanto, B. (2020). Discover the Legal Concept in the Sociological Study. Substantive Justice International Journal of Law, 3(1), 94-108, http://dx.doi.org/10.33096/sjijl.v3i1.69

Suka'arsana, I Komang. (2018). Penegakan Hukum Terhadap Tindak Pidana Pencurian Ikan. Jurnal Hukum Pidana dan Pembangunan Hukum, 1 (1), 1-5.

Taufik, Kinanti Kusumawardani. (2017).IUU Fishing as Transnational Organized Crime' Discourse: A Policy Argumentation Analysis. Paper prepared for presentation at the ISA International Conference, Hong Kong.

Trusts, Pew. (2017). How to End Illegal Fishing from Coastal Waters to the High Seas, Criminals are Robbing the Oceans and Hurting Economies. A Brief from the PEW Charitable Trusts. 
Wahjono, Pujo. (2010). Transnational Crime and Security Threats in Indonesia.Strategy Research Project, US Army War College, Pennsylvania,

Zebua, N. D. \& Ramli. (2014).Analisis Pengaruh Jumlah Armada, Jumlah Nelayan, Pdrb, Dan Investasi Terhadap Produksi Perikanan di Wilayah Nias (Analisis Data Panel). Jurnal Ekonomi dan Keuangan, 2 (8), 463-474.

\section{Internet}

Gunnar Stolsvik, “Transnational organized fisheries crime as a maritime security issue,"http://www.un.org/Depts/los/consultative_process/documents/9_gunn arstolsvikabtract.pdf - diakses 20 Mei 2011

\section{Peraturan}

Convention Against TransnationalOrganized Crime 2000

Kitab Undang-Undang Hukum Pidana

UU No. 45 tahun 2009 tentang Perikanan (Lembaran Negara Tahun 2009 Nomor 154 5073 Tambahan Lembaran Negara Nomor 5073) 